\section{Punishment of free-operant avoidance responding in rats with septal lesions}

\author{
FRANK J. SODETZ and STEVEN KOPPELL \\ Walter Reed Army Institute of Research, Washington, D.C. 20012
}

Rats with septal lesions and control rats were run on a Sidman avoidance procedure until performance was stable. Each avoidance response was then punished by an electric shock of the same intensity but of shorter duration than the shocks delivered by the avoidance program. No difference was observed between the septal and control group in the effect of punishment on overall response rate. However, introduction of punishment seriously disrupted the temporal distribution of the avoidance responses of both the septal and the control groups, and only the performance of the septal group recovered from this disruptive effect of punishment.

Rats with septal lesions have frequently been run in studies in which punishment has been used to suppress some appetitively maintained operant. In such studies, conflicting contingencies have been arranged that permitted avoidance of punishment only at the cost of losing appetitive reinforcers or acquisition of reinforcers at the cost of exposure to punishment. In such studies, it has been demonstrated repeatedly that electric shock is less effective in suppressing appetitive responding in rats with septal lesions than it is in suppressing the responding of intact animals (Fried, 1969, 1970; Kaada, Rasmussen, \& Kveim, 1962; Schwartzbaum \& Spieth, 1964; Thomas, Hostetter, \& Barker, 1968).

Because rats with septal lesions tend to have higher unpunished response rates for food or water reinforcement and because response-contingent electric shock is less effective in suppressing appetitively maintained responding, the effects of septal ablation have at times been characterized as either motivational changes (Harvey, Lints, Jacobson, \& Hunt, 1965) or a change in the ability of the animal to withhold a response (McCleary, 1966). One way in which the adequacy of these interpretations could be assessed would be to administer response-contingent electric shock for a response that was not reinforced with either food or water and which occurred at a lower rate in rats with septal lesions.

The present study was designed to examine the effects of response-contingent electric shock on Sidman avoidance responding. Rats with septal lesions are known to emit Sidman avoidance responses at lower rates than intact animals (Morgan \& Mitchell, 1969).

\section{SUBJECTS}

The Ss were seven adult male Long Evans rats ${ }^{1}$ weighing between 400 and $450 \mathrm{~g}$ at the start of the experiment.
All animals were maintained in individual cages in which Purina Lab APPARATUS

The animals were run in two Foringer $1107 \mathrm{R}$ operant conditioning chambers equipped with a single response lever and grid floors. The chambers were enclosed in sound-attenuating booths. Electric shock was delivered to the shock grids through relay shock scramblers by Foringer constant-current shock sources. The shock sources were calibrated to deliver shock of $1 \mathrm{~mA}$ to the grids with a $50 \mathrm{k} \mathrm{ohm}$ resistor serving as a dummy load in place of an animal. Shocks delivered by the avoidance program were $500 \mathrm{msec}$ long. Response-contingent shocks were of the same intensity and were $250 \mathrm{msec}$ long. All programming was done with BRS Foringer solid state modules, and data were recorded on electromechanical counters. During sessions, a masking noise (approximately $75 \mathrm{~dB}$ ) was on in both operant chambers.

SURGERY AND HISTOLOGY

Four rats underwent surgery to produce stereotaxically placed bilateral lesions in the septal region by RF thermocoagulation using a Grass LM-3 lesion maker. Each animal was anesthetized with sodium pentobarbital $(60 \mathrm{mg} / \mathrm{kg})$ following pretreatment with atropine sulfate $(.10 \mathrm{mg})$ to reduce nasopharyngeal secretion. An attempt was made to produce complete bilateral destruction of the septal region in each experimental animal. The lesion coordinates, determined empirically in a series of pilot animals, were $1.8 \mathrm{~mm}$ rostral to bregma, $1.5 \mathrm{~mm}$ lateral to the midline, and $5.5 \mathrm{~mm}$ ventral to the surface of the cortex, with incisor and ear bars at the same height. Three control animals received a sham operation, during which an electrode was inserted to a depth of $3 \mathrm{~mm}$ below the surface of the cortex and Chow and water were available ad lib. withdrawn. All animals were given a 3-week postoperative recovery period following surgery.

At the conclusion of the experiment, all animals were sacrificed with an overdose of sodium pentobarbital. Each was perfused intracardially with saline, followed by 10\% Formalin, after which each brain was blocked, frozen, and sectioned at $30 \mathrm{micra}$. Every fourth section through each lesion was stained with cresyl violet.

PROCEDURE

Following postoperative recovery, the animals used in the study were first run for 50 daily, 100-min Sidman avoidance sessions with several different response-shock (RS) and shock-shock (SS) intervals to insure stable performance and minimize the probability that introduction of punishment would completely eliminate avoidance responding. All animals were then run for one experimental session each day. Each session lasted $100 \mathrm{~min}$ and was divided into two 50-ritin periods. The same schedule parameters were used throughout the experiment. The RS interval was $18 \mathrm{sec}$, and the SS interval was 6 sec. All Ss were run on this avoidance schedule alone for 14 sessions. Beginning with the 15th session, each response was punished with a brief electric shock ( $250 \mathrm{msec}$ ). Ss were run under this punishment condition for 28 sessions. At completion of these sessions, the punishment coutingency was made selective, i.e., only interresponse times (IRTs). shorter than $14 \mathrm{sec}$ were punished. Longer IRTs were never punished. Ss were run in this condition for 28 additional sessions. Finally, the punishment contingency was removed and all Ss were run for 14 sessions of avoidance alone.

\section{RESULTS}

The lesions produced were confined largely to structures rostral to the decussation of the anterior commissure. The exceptions were some partial destruction of the postcommissural medial septal nuclei and columns of the fornix. In all $\mathrm{Ss}$, approximately the rostral $20 \%$ of the triangular septal nucleus was ablated. In the precommisural septal region, destruction of the medial and lateral septal nuclei was complete. Bilaterally, approximately the medial $50 \%$ of the nucleus accumbens septi was ablated, as were both the nucleus of the diagonal band and the diagonal band proper. The precommissural fornix was ablated in all Ss.

Avoidance Behavior

The major features of the avoidance performance of both the septal and control groups are summarized in Fig. 1. Panel A presents indices of the 

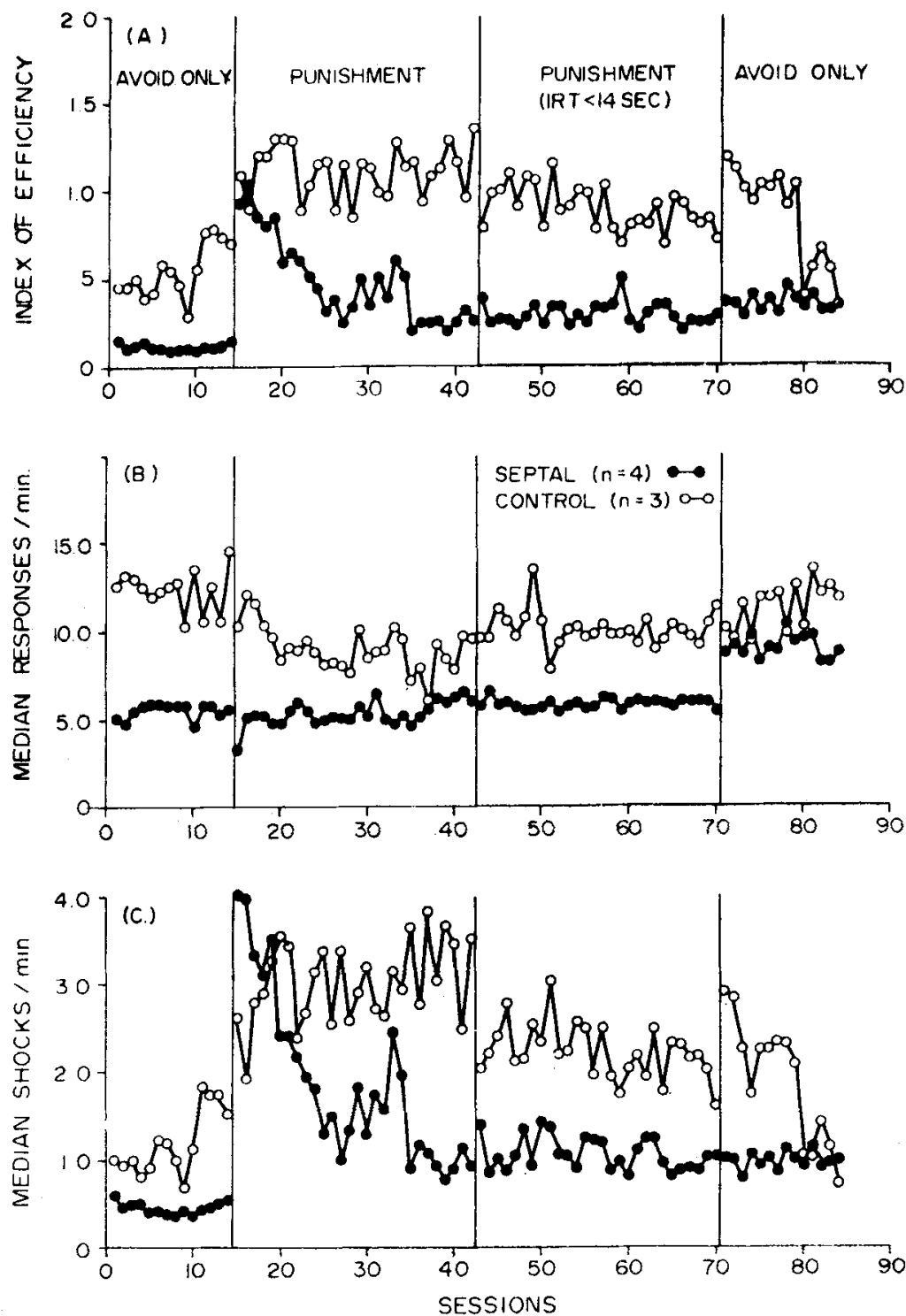

Fig. 1. Summary of the major features of the avoidance performance of the septal and control groups across all sessions run in the study.

efficiency of avoidance, calculated by using the data presented in Panels $B$ and $C$. Because the index of efficiency (McIntire, Davis, Cohen, \& French, 1968) considers both shock rate and the number of responses emitted to maintain that rate, such a measure is a more suitable indicator of overall avoidance performance than is either response or shock rate alone. The index of efficiency was obtained using the formula: Efficiency $=[($ Number of shocks received)/(Maximum number of shocks possible $)] \times[(N u m b e r$ of responses emitted + Minimum number of responses required to avoid all shocks)/(Minimum number of responses required to avoid all shock)]. Lower scores reflect greater efficiency.

Panels $B$ and $C$ of Fig. 1 present
14 sessions preceding the introduction of punishment. A Mann-Whitney $U$ test of the difference in efficiency of the septal and control groups during the last three sessions preceding introduction of punishment yielded a probability of .057 that the difference could have been due to chance ( $n_{1}=3, n_{2}=4$, one-tailed). In the septal group, the efficiency scores ranged from .02 to .37 with a median of .18 , while in the control group, the range of scores was from :16 to 1.03 with a median of .92 . Both the median response rate $(p<.057$, one-tailed) and median shock rates $(p<.057$, one-tailed) during these sessions (Fig. 2, Panels B and C) were lower in the septal group.

Figure 2 presents curves describing the conditional probability of an avoidance response during successive class intervals of the RS interval. The probabilities are conditional upon an opportunity to respond and the measure is known as interresponse times per opportunity (IRTs/OPP). Anger (1963) has shown that IRTs/OPP is a useful measure for characterizing the temporal distribution of avoidance responses. As can be seen from Fig. 2, Panel $A$, the septal group had a higher probability of emitting responses late in the $R S$ interval. This distribution of responding permitted more shocks to be avoided with fewer responses and was reflected in superior efficiency scores.

\section{Punishment}

Introduction of $100-\mathrm{msec}$ response-contingent electric shocks beginning with Session 15 reduced the efficiency of both the septal and control groups.s (Fig. 1, Panel A). For Sessions 15-17, every animal was less efficient; however, there were no differences in the efficiency scores of the two groups. During the initial three punishment sessions, there was no significant reduction in response rate in either group. Two of the animals with septal lesions emitted more responses during these sessions than they did in Sessions 12-14, and two animals emitted fewer responses. Two control animals emitted fewer responses; the rate of response of the remaining animal increased.

All of the animals received more shocks from the avoidance program during the three initial punishment sessions. In the absence of any decrease in response rate, the observed increase in shock rates could only have resulted from a change in the temporal distribution of avoidance responses. This change can be observed by comparing Panels A and B of Fig. 2. The IRT/OPP functions of both groups were essentially flat beyond the first 4 sec of the RS interval, and the 
probability of a response did not rise above .10.

Although both groups suffered elevated shock rates with the introduction of punishment, the septal group which had maintained lower shock rates than the control group received more shocks than the controls during the first three punishment sessions $(p<.057$, two-tailed $)$. One possible explanation for this reversal may be that the septal group had a higher probability of accepting two or more successive shocks without an intervening response once punishment was introduced. Before punishment was introduced, the septal group (.07) and the control group (.09) had about equal probabilities of accepting successive shocks. With the introduction of punishment, the probability increased to .64 for the septal group while increasing to only .20 for the control group. These data indicate that the septal group not only took more shocks, but that they received more repetitive shocks, i.e., had a lower probability of emitting a response each time a shock was delivered by the avoidance program.

Throughout succeeding punishment sessions (15-42), the efficiency of the control animals did not improve (Fig. 1, Panel A). Their shock rates (Fig. 1, Panel C) did not improve and their response rates (Fig. 1, Panel B) declined slightly from 11.60 responses/min (Sessions 15-17) to 9.66 responses/min (Sessions 40-42). In contrast, the shock rates of the animals with septal lesions declined steadily from approximately 4 shocks/min to less than 1 shock/min, with no change in response rate. The lower shock rates were reflected in the lower efficiency scores (Fig. 1, Panel A) of the septal group during the later punishment sessions.

It should be emphasized that the improved efficiency of the septal group did not result from an increase in response rate but occurred as a result of a temporal redistribution of responses. Comparison of Panels $B$ and $\mathrm{C}$ of Fig. 2 indicates that during later punishment sessions $(40-42)$, the probability of a response during the laiter part of the RS interval increased and the shape of the function more nearly approximated that obtained from the avoidance sessions alone (Fig. 2, Panel A). The IRT/OPP function of the controls may also have changed slightly, but any difference between Panels $B$ and $C$ was small in contrast to the septal group.

Selective Punishment

During Sessions 43-70, only IRTs shorter than $14 \mathrm{sec}$ were punished. Because rats with septal lesions had been shown to have a higher probability of responding during the
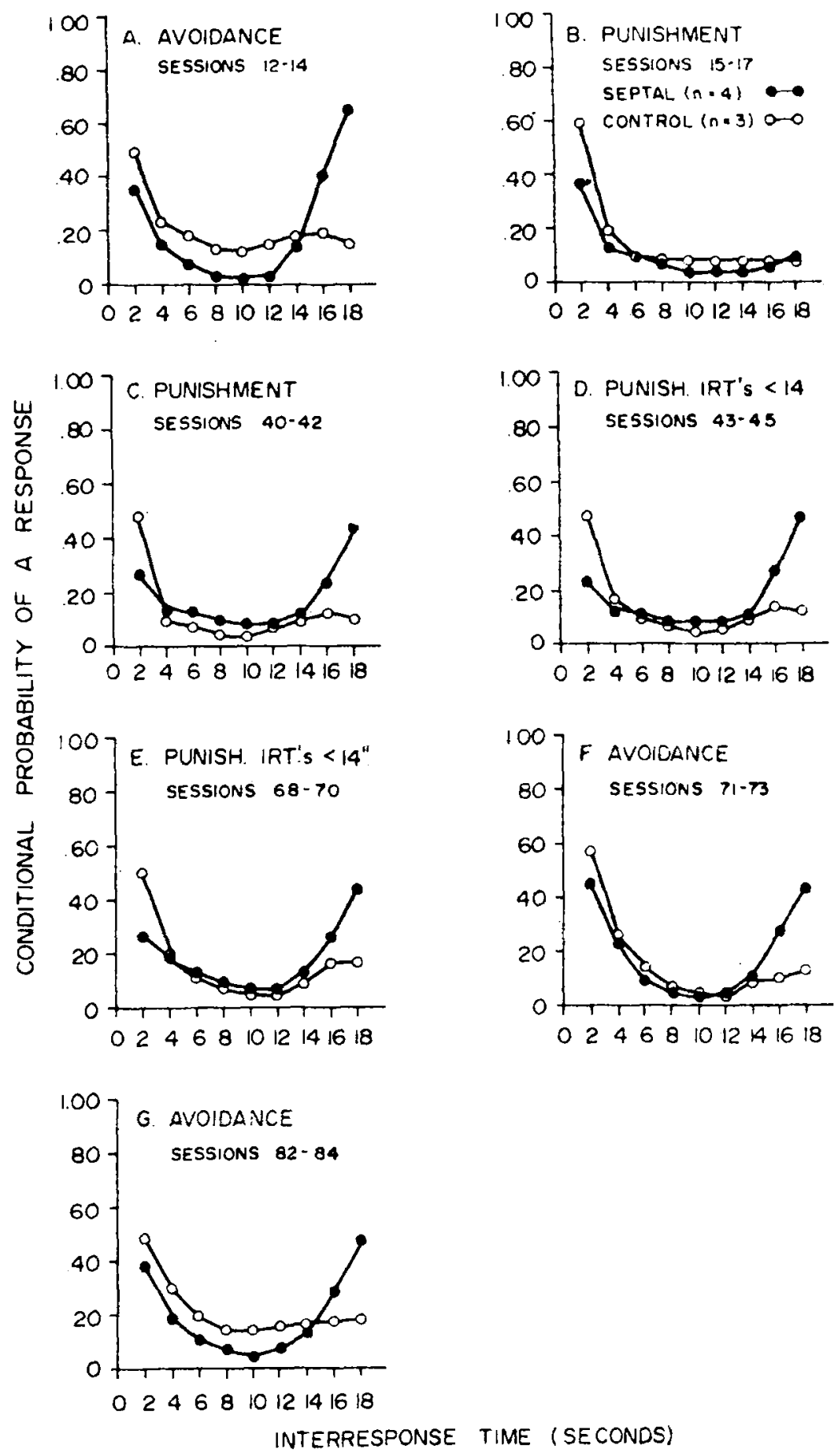

Fig. 2. IRT/OPP functions obtained from the septal and control groups. Each data point is based on the total number of responses observed in a particular class interval of the RS interval for all the sessions indicated. Panels A-G depict performance at critical points during the study.

later part of the RS interval (Morgan \& Mitchell, 1969; Sodetz, 1970), it was anticipated that eliminating the punishment contingency for IRTs longer than $14 \mathrm{sec}$ would have differentially affected the two groups of Ss. As is apparent from Fig. 1 and Panels $\mathrm{D}$ and $\mathrm{E}$ of Fig. 2, this change in the punishment contingency had no notable effect on the performance of either group.

Withdrawal of Punishment

Beginning wich Session 71 , avoidance responses were no longer punished. The shock rates of the septal group did not decrease (Fig. 1, 
Panel C) below those maintained during punishment sessions; however, the response rates of the septal group did increase above both their punished rates (Sessions 15-70) and their prepunished rates (Sessions 1-14). A Mann-Whitney $U$ test of the difference in median response rates for Sessions 11-14 and Sessions 78-80 ( $<<.028$, two-tailed) confirmed this difference. The increased rate of response without a reduction in shock rate may have resulted in some loss of efficiency (Fig. 1, Panel A).

Initially, the control group continued to respond at about the same rate as during punishment sessions. Then, response rates increased gradually until they were not notably different from their initial prepunishment response rates. Shock rates decreased precipitously during the final few sessions and efficiency was markedly improved. In short, the purformance of the control group was no different from what it had been before punishment was introduced while the performance of the septal group continued to be impaired. Comparison of Panels $A$ and $G$ of Fig. 2 indicates the similarity in the pre- and postpunishment IRT/OPP functions of the control group, while the postpunishment IRT/OPP function of the septal group is more similar to that obtained during punishment sessions (Fig. 2, Panels C-E).

\section{DISCUSSION}

The results of the present study, when taken together with those of other studies in which response-contingent electric shock has been used to control responding, support the conclusion that septal ablation changes the functional relationship between behavior and its aversive consequences. There have been a number of attempts to account for this effect of ablation and the present data bear directly on two of these, motivational interpretations (e.g., Harvey et al, 1965) and disinhibition hypotheses (e.g., McCleary, 1966).

In a number of studies of the suppressive effects of punishment on the consummatory as well as the instrumental behavior of rats with septal lesions, it has been possible to interpret the results in terms of enhanced motivation related to the reinforcer maintaining performance. This interpretation was possible because increased consumption of water (Harvey \& Hunt, 1965) and increased operant responding for food (Lorens \& Kondo, 1969) had been demonstrated in rats with septal lesions. However, Winocur \& Mills (1969) and others have weakened the motivational interpretation by demonstrating that punishment is also less effective in suppressing the general activity of rats following septal ablation. The data of the present study extend existing data on the effects of punishment of consummatory behavior, appetitively maintained instrumental responding, and general activity to behavior maintained under aversive control and, in doing so, weaken further the argument that enhanced motivation for food or water underlies the deficient response to punishment.

Generally, the most typical effect of response-contingent shock is suppression of responding; however, under certain conditions, it may disrupt performance in other ways, as evidenced by the present study, or it may even paradoxically enhance performance if requisite conditions are met (Morse \& Kelleher, 1970). Given what is known of the effects of response-contingent shock and the outcome of the present study, it seems reasonable to suggest that the disinhibition frequently reported in studies of septal ablation may be but one limited manifestation of a more general effect of septal ablation related to the control of behavior by aversive consequences.

\section{REFERENCES}

ANGER, D. The role of temporal discrimination in the reinforcement of Sidman avoidance behavior. Journal of the Experimental Analysis of Behavior, $1963,6,477-606$.

FRIED, P. A. Effects of septal lesions on confict resolution in rats. Journal of Comparative \& Physiological Psychology, $1969,69,375-380$.

FRIED, P. A. Pre- and post- operative approach training and conflict resolution by septal and hippocampal lesioned rats. Physiology \& Behavior, 5, 975-979.

HARVEY, J. A., LINTS, C. E., JACOBSON,
L. E. \& HUNT, H. F. Effects of lesions in the septal area on conditioned fear and discriminated instrumental punishment in the albino rat. Joumal of Comparative \& Physiological Psychology, 1965, 59, 37-48.

KAADA, B. R., RASMUSSEN, E. W., \& KVIEM, O. Impaired acquisition of passive avoidance behavior by subcallosal, septal, hypothalamic and insular lesions in rats. Journal of Comparative \& Physiological Psychology, 1962, 55, $661-670$.

LORENS, S. A., \& KONDO, C. Y. Effects of septal lesions on food and water intake and operant responding for food. Physiology \& Behavior, 1969, 4, 729-732. MCCLEARY, R. A. Response-modulating functions of the limbic system: Initiation and suppression. In $\mathbf{E}$. Stellar and $F$. $M$. Sprague (Eds.), Progress in physlological prychology. Vol. 1. New Yodk: Academic Press, 1966. Pp. 209-272.

McINTIRE, R. W. DAVIS, H., COHEN, $S$. L., \& FRENCH, E. O. Sidman avoidance performance under punishment and non-contingent shock conditions. Psychological Reports, 1968,22 , $897-903$.

MORGAN, J. M., \& MITCHELL, J. C. Septal lesions enhance delay of responding on a free-operant avoidance schedule. Psychonomic Science, 1969. 16, 10-11.

MORSE, W. H. \& KELLEHER, R. T. Schedules as fundamental determinants of behavior. In W. N. Schoenfeld (Ed.), The theory of reinforcement schedules. New York: Appleton-Century-Crofts, 1970. Pp. 139-186.

SODETZ, F. J. Septal ablation and free-operant avoidance behavior in the rat. Physiology \& Behavior, 1970, 5 , 773-777.

SCHWARTZBAUM, J. S., \& SPIETH, T. M. Analysis of the response-inhibition concept of septal function in "passive avoidance" "behavior. Psychonomic Science, 1964, 1, 145-146.

THOMAS, G. J., HOSTETTER, G., \& BARKER, D. J. Behavioral functions of the limbic system. In E. Stellar and J. M. Sprague (Eds.), Progress in physiological psychology. Vol. 3. New York: Academic Press, 1968. Pp. 229-311.

WERTHEIM, G. A. Some sequential aspects of IRT's emitted during Sidman avoidance behavior in the white rat. Journal of the Experimental Analysis of Behavior, 1965, 8, 9-15.

WINOCUR, G., \& MILLS, J. A. Hippocampus and septum in response inhibition. Journal of Comparative \& Physiological Psychology, 1969, 67, 352-357.

\section{NOTE}

1. In conducting the research described in this report, the investigators adhered to the "Guide for Laboratory Animal Facilities and Care," as promulgated by the Committee on the Guide for Laboratory Animal Facilities and Care of the Institute of Laboratory Animal Resources, National Academy of Science-National Research Council. 